\title{
Acoustic Approach to Determining Seabed Substrates Distribution at Mandi Darah Island, Sabah
}

\author{
Mohd Shukri Mohd Yusopa, Mohd Norsyarizad Razalia, \\ Nazirah Md Tarmizi ${ }^{\text {, }}$ Mohd Najib Abdul Ghani Yolhamida, \\ M. N. Azzeria, Ainul Husna Abdul Rahmana
}

Marine ecosystems and natural habitat play the important role of the Earth's life support system. They significantly contribute to economies and food safety and help preserve ecological processes. However, the devastation of the marine ecosystem in Malaysia due to the human factor and climate change is quite alarming. Therefore, spatial marine information, especially on the distribution of seabed substrates and habitat mapping, are of utmost importance for marine ecosystem management and conservation. Traditionally, seabed substrate and habitat mapping were classified based on direct observation techniques such as photography, video, sampling, coring and scuba diving. These techniques are often limited due to water clarity and weather conditions and only suitable for smaller scale surveys. In this study, we employed an acoustic approach using

\section{KEY WORDS}

$\sim$ Seabed substrate

$\sim$ Acoustic signal

$\sim$ RoxAnn GD-X

$\sim$ Mandi Darah island

$\sim$ Single beam

$\sim$ Habitat mapping

a. Universiti Pertahanan Nasional Malaysia, Kuala Lumpur, Malaysia

e-mail: mohd.shukri@upnm.edu.my

b. Universiti Teknologi MARA, Perlis, Malaysia

e-mail: nazir230@uitm.edu.my

doi: 10.7225/toms.v10.n02.007

This work is licensed under (cc) BY

Received on: 28.06.2021/Revised on: 13.10.2021/Accepted on: 19.10.2021/Published: 21.10.2021 the RoxAnn Acoustic Ground Discrimination System (AGDS) with a high-frequency single-beam echo sounder to examine the distribution of seabed substrate at the Mandi Darah Island, Sabah. The acoustic signals recorded by AGDS are translated into hardness and roughness indices which are then used to identify the unique characteristics of the recorded seabed types. The analysis has shown that fifteen types of substrates, ranging from silt to rough/some seagrass, have been identified and classified. The findings demonstrated that the acoustic method was a better alternative for seabed substrate determination than the conventional direct observation techniques in terms of cost and time spent, especially in large scale surveys. The seabed substrate dataset from this study could be used as baseline information for the better management and conservation of the marine ecosystem.

\section{INTRODUCTION}

Approximately $71 \%$ of our planet is covered by oceans and seas which contribute to major natural and economic resources of the world. Marine ecosystem and natural habitat play the important role of the Earth's life support system. They significantly contribute to economies and food safety and help preserve ecological processes. However, marine biodiversity and ecosystem are at risk. Marine habitats are lost, coral reefs devastated, the seas polluted and fish resources depleted (Fakiris et al., 2019). Coral reefs are important ecological and economic resources in a number of countries, including Malaysia. They are important ecosystems for marine life, protect the coast from stronger waves and serve as a source of income to millions of people. In Malaysia, coral reefs cover almost 4,006 square km, are a habitat for more than 700 fish species (Marine and coastal 
biodiversity, 2015). The average living coral numbers in Malaysia have dropped to $41.32 \%$ and have been declining since 2015 (Reef Check Malaysia, 2020). Therefore, an effort to protect and preserve the marine ecosystem is crucial for the sustainability of marine life. However, the viable and effective preservation and protection of the marine ecosystem greatly depend on sufficient information on the spatial extent, geographical range and ecological characteristics of the resource or habitat of interest. Thus, the need to accurately determine seafloor characteristics and map habitat is evident in marine spatial planning, management and conservation of marine biodiversity and the ecosystem (Herkül et al., 2017). Other than that, accurate information on seafloor topography and seabed composition are likewise important for marine engineering, pipe or cable laying, marine geological studies, as well as naval operations, especially those involving submarines and mine warfare (Baker \& Harris, 2012; Coiras et al., 2007; Hasan et al., 2014).

Traditionally, information on seafloor types and marine habitats were determined based on direct observation techniques such as photography, video, sampling, coring, or scuba diving (Biondo \& Bartholomä, 2017). While direct observation techniques are suitable for seabed description, they are subject to individual expert interpretations which may differ from one another. Direct observation techniques also depend on water transparency and weather conditions and are time consuming (Schimel et al., 2010). Technological advancements made possible the application of the indirect method that uses the remote sensing approach for habitat mapping purposes (Hamana \& Komatsu, 2016). The remote sensing approach to habitat mapping can be divided into two distinct types, namely, optical remote sensing which uses the electromagnetic spectrum to capture an image from an airborne platform or satellite, and acoustic remote sensing which uses an acoustic sensor attached to a surface vessel for marine mapping. Optical satellite remote sensing devices commonly used for marine habitat mapping are Landsat (Hossain et al., 2016), ALOS (Mustapha et al., 2014), and high resolution satellite imagery, such as Quickbird and World View 2 (Conti et al., 2020; Garcia et al., 2015; Papakonstantinou et al., 2017). Although optical remote sensing is highly efficient for mapping larger areas, it is limited to shallow waters due to the light attenuation in the water column. This method can usually make measurements up to the maximum depth of $30 \mathrm{~m}$, provided the local conditions are favorable and the sea is calm (Jawak et al., 2015; Lecours et al., 2018). On the contrary, the acoustic method has no restrictions with respect to water depth and clarity (Tajam \& Mokhtar, 2019; Hamana \& Komatsu, 2016).
An acoustic system, such as a single beam echo sounder (SBES), sidescan sonar (SSS), and multibeam echo sounder (MBES) has become an option, as it is capable of overcoming the setbacks of direct observation techniques (Alevizos et al., 2015). Therefore, this study will employ a single beam acoustic system to examine the distribution of seabed substrate at the Mandi Darah Island. The seabed substrate map based on acoustic data will also be used as a preliminary study for site suitability selection for the proposed installation of the Wave Energy Converter (WEC) system.

\section{MATERIALS AND METHOD}

\subsection{Study Area Description}

The study was conducted at the Mandi Darah Island (Figure 1) which is $240 \mathrm{~km}$ from Kota Kinabalu. The Mandi Darah Island is a small island located ( $\left.06^{\circ} 55^{\prime} 59^{\prime \prime} \mathrm{N}, 117^{\circ} 20^{\prime} 19^{\prime \prime} \mathrm{E}\right) 60 \mathrm{~km}$ from Kudat, Sabah Malaysia. The island has the surface of only $2.5 \mathrm{~km}^{2}$, with the highest peak approximately 529 meters above sea level (Monaliza \& Samsur, 2011). This island is one of the islands belonging to the Tun Mustapha Park - a Kudat-Banggi Priority Conservation Area. This area is known for the presence of migratory species, large and diverse coastal and marine ecosystems, as well as productive fishing grounds (Sabah Parks, 2017). There are an estimated 35 houses on the island, populated by the Ubian tribes who work as fishermen (Suadik et al., 2018).

\subsection{Data Collection}

The survey period was May 26 - June 15, 2018 and covered approximately 11.7 square kilometers. The data were obtained from a single beam echo sounder, while the back scatter data were processed using the RoxAnn GD-X unit manufactured by Sonavision Ltd UK throughout the survey. Since the study area was in shallow water, a single beam echo sounder was operated at the frequency of $200 \mathrm{kHz}$, while a Fugro Marinestar 9205 GNSS Receiver was used for accurate positioning.

\subsubsection{RoxAnn GD-X}

RoxAnn GD-X is commonly used for marine environmental monitoring and habitat mapping (Brown et al., 2005; Rukavina, 2001) and apart from depth measurement, it can also classify seabed types owing to its built-in acoustic seabed classification function (Che Hassan, 2014). Generally, the RoxAnn acquisition 


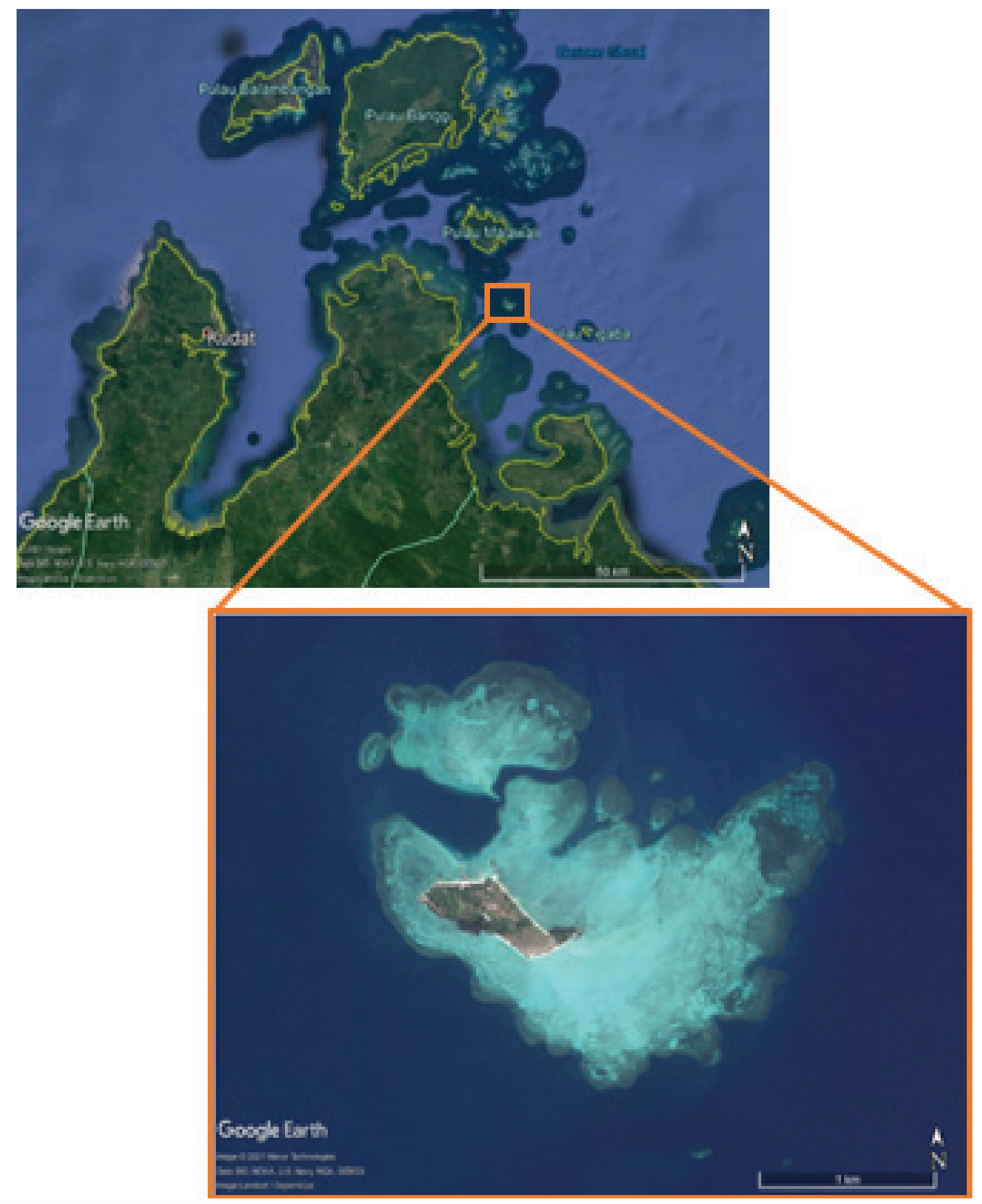

Figure 1.

Location of study area around the Mandi Darah Island (Google earth, 2021). 


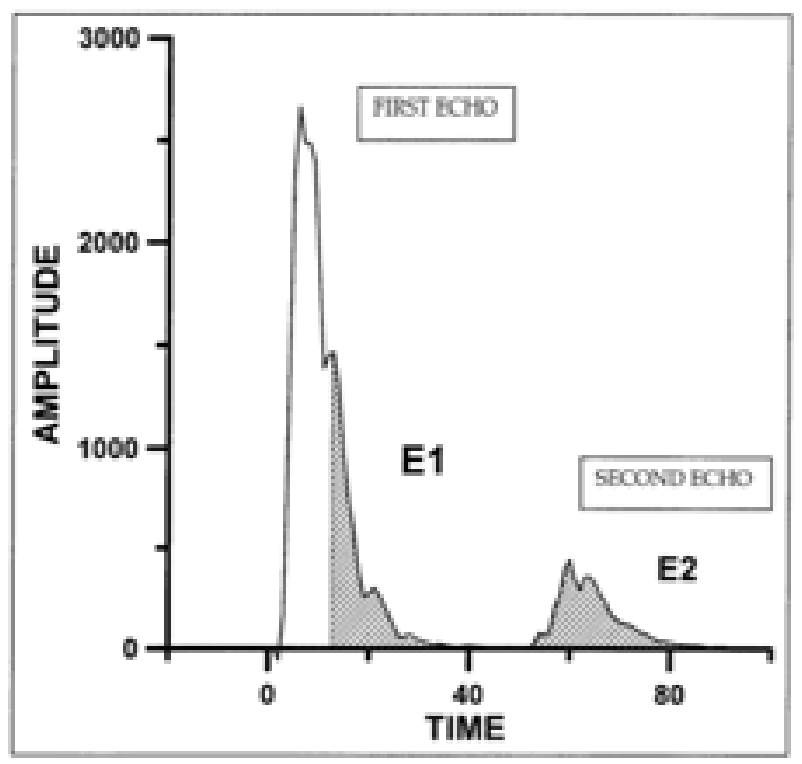

Figure 2.

Acoustic signal processing of the reflection of the first and second echo from the bottom, recorded by the RoxAnn system; the shaded area is integrated to form two indices E1 and E2 (Hamilton, 2001). software selects two distinct echoes, E1 and E2, that are reflected from the seabed (Foster-Smith \& Sotheran, 2003). The E1 is a decaying echo after the initial peak and mostly used to determine the roughness of the ground surface, while the second echo, E2, reflects twice from the seabed and is thus strongly affected by seabed hardness (Figure 2).

A complete AGDS incorporates the input of real time, georeferenced survey and all valid E1 and E2 signals collected and sent to the computer for further processing using the RoxMap Scientific software. The acquired acoustic signatures, consisting of the roughness index (E1) and the hardness index (E2), are plotted against each other based on the predefined RoxAnn library known as the RoxAnn Square, by referring to Yap (2017) as in Figure 3. The RoxAnn Square uses colored boxes where the $x$ axis represents the index of hardness (E2) and the $y$ axis the index of roughness (E1). All the data in the box correspond to a particular substrate type, based on the roughness and hardness indices. Substrates such as rock and gravel, generate high E1 and E2 values, whereas the muddy substrate has low E1 and E2 values since it absorbs the sound from the echo sounder due to its flatness (Cholwek et al., 2000). The data from RoxAnn were also combined with the GPS position, depth and time for further processing using the geographical information system (GIS) to produce substrate maps.

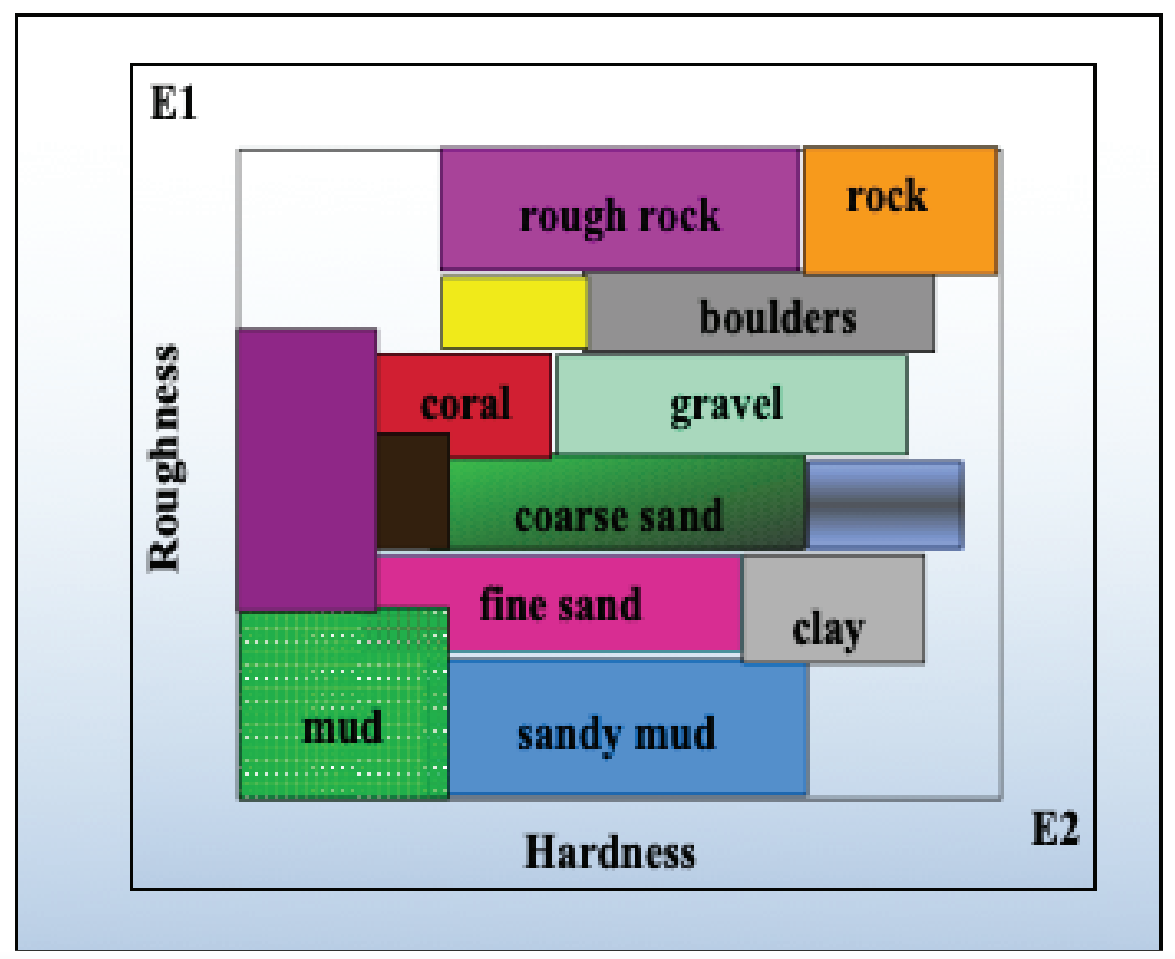

Figure 3.

RoxSquare calibration color box showing different substrates obtained using E1 and E2 echoes (Yap,2017). 


\subsubsection{AGDS Survey Methodology}

In general, the AGDS works on the principle that when an acoustic wave emitted by an echo sounder is reflected off the seabed, it is attenuated by the properties of the reflecting surfaces (Chivers et al., 1990). The AGDS is better used to differentiate between various seabed habitats, because some of the substrate features could give different acoustic reflections. For instance, the coral substrate has medium range roughness (E1) and hardness (E2) values, while the substrates of rocks and gravel generates high E1 and E2 values (Tajam and Mokhtar, 2019). Prior to data collection, the RoxAnn system was calibrated to synchronise all system components where substrate conditions were known. An initial calibration on mud was performed in the vicinity of the Mandi Darah Island jetty. Upon completion of the initial calibration on mud, the AGDS was ready to be trained on multiple coral/non-coral substrates within the surveyed area.

The purpose of this calibration was to configure a scale that would cover all possible substrates, from very soft substrates, such as mud, to extremely hard substrates, such as bedrock found within the survey area. This procedure also required a diver to mark the substrate of interest with rope and a marker buoy. The survey vessel then proceeded to the selected location of the substrate of interest to record the acoustic signature. The recorded acoustic signals were stored in the RoxSquare library. 15 types of substrate, consisting of coral and non-coral substrates, were trained and identified prior to the beginning of the survey. During the survey run, the data-logging software RoxMap Scientific was used for data acquisition. The survey tracks were well-spaced between each other. The vessel sailed at the average speed of 4-5 knots, parallel to the island. The recorded data were then processed using the Surfer 15 software to produce a seabed substrate map. Three stages of processing were involved in the Surfer 15 processing. The first stage required the filtering of spikes in the raw data, caused by echo interference due to shallowness and hard substrates, such as corals. The second stage involved the importation of data variables for $\mathrm{x}, \mathrm{y}$ and substrate classes, while the third stage involved spatial interpolation using the point kriging method, with a 35 meter resolution spacing to obtain an interpolation map for the substrate's distribution.

\section{RESULTS AND DISCUSSION}

A total of 34,206 signals from the RoxAnn were recorded with the high frequency echo sounder in the survey period. Figure 4 shows a trackline with different colours representing seabed substrate variations in the survey area. 15 types of substrate have been identified in the survey area, as shown in

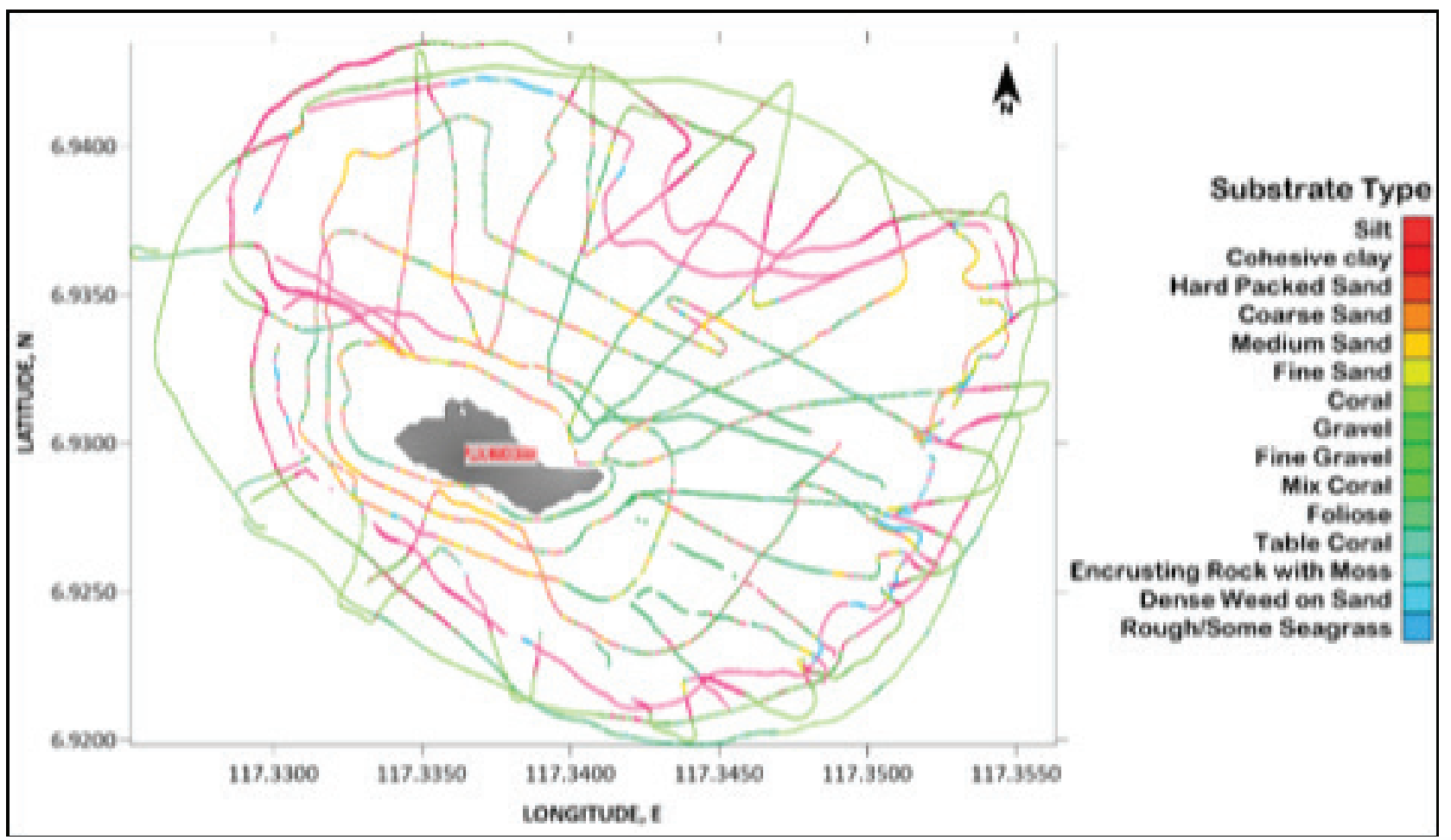

Figure 4.

Trackline of the 2D AGDS survey carried out at the Mandi Darah Island. 
Table 1. The results from the data obtained show that gravel was the most dominant substrate, covering $47,656.33 \mathrm{~m}^{2}$ (39.95\%) of the study area, followed by hard-packed sand $\left(30,891.86 \mathrm{~m}^{2}\right.$, i.e. $25.90 \%)$, fine gravel $\left(15,851.52 \mathrm{~m}^{2}\right.$, i.e. $\left.13.29 \%\right)$ and cohesive clay $\left(11,837.30 \mathrm{~km}^{2}\right.$, i.e. $\left.9.92 \%\right)$. Meanwhile, dense weed on sand and silt represented a minute portion of the substrates, with less than
$3 \mathrm{~m}^{2}$ or $0.002 \%$ of total signal coverage, followed by fine sand $84.55 \mathrm{~m}^{2}(0.07 \%)$ and coral $313.12 \mathrm{~m}^{2}(0.26 \%)$.

The depth, determined by RoxAnn, varies between 2 and 23 $\mathrm{m}$, as shown in the bathymetry map in Figure 5 . The depth is bigger in the west of the island and shallower in the east. Some shallow water areas in the east of the island surfaced during low tides.

Table 1.

Substrate percentages determined at the Mandi Darah Island.

\section{Number of Signal and Coverage of All Substrate}

\begin{tabular}{|c|c|c|c|c|c|}
\hline CODE & SUBSTRATE & NO OF SIGNAL & $\%$ OF SIGNAL & COVERAGE $\mathbf{m}^{2}$ & $\%$ OF COVERAGE \\
\hline 1 & $\begin{array}{l}\text { Rough/Some } \\
\text { Seagrass }\end{array}$ & 1,391 & 4.07 & $1,980.88$ & 1.66 \\
\hline 2 & $\begin{array}{l}\text { Dense Weed on } \\
\text { Sand }\end{array}$ & 14 & 0.04 & 2.46 & 0.00 \\
\hline 3 & $\begin{array}{l}\text { Encrusting Rock } \\
\text { with Mosses }\end{array}$ & 1,540 & 4.50 & $1,354.81$ & 1.14 \\
\hline 4 & Table Coral & 1,503 & 4.39 & $2,794.53$ & 2.34 \\
\hline 5 & Foliose & 2,210 & 6.46 & $2,330.66$ & 1.95 \\
\hline 6 & Mix Coral & 2,131 & 6.23 & $1,842.65$ & 1.54 \\
\hline 7 & Fine gravel & 3,486 & 10.19 & $15,851.52$ & 13.29 \\
\hline 8 & Gravel & 5,714 & 16.70 & $47,656.33$ & 39.95 \\
\hline 9 & Coral & 893 & 2.61 & 313.12 & 0.26 \\
\hline 10 & Fine Sand & 163 & 0.48 & 84.55 & 0.07 \\
\hline 11 & Medium Sand & 2,903 & 8.49 & 734.45 & 0.62 \\
\hline 12 & Coarse Sand & 1,962 & 5.74 & $1,619.27$ & 1.36 \\
\hline 13 & Hard Packed Sand & 8,638 & 25.25 & $30,891.86$ & 25.90 \\
\hline 14 & Cohesive Clay & 1,647 & 4.81 & $11,837.30$ & 9.92 \\
\hline \multirow[t]{2}{*}{15} & Silt & 11 & 0.03 & 1.69 & 0.00 \\
\hline & TOTAL & 34,206 & 100.00 & $119,296.06$ & 100.00 \\
\hline
\end{tabular}

The 3D interpolation map, showing the distribution of seabed substrates around the Mandi Darah island (Figure 6), was produced using the Surfer 15 software. Observations show that there aren't many corals around the island. They are mostly scattered to the south and east in the gravel dominant area, with a small percentage of coral found to the west of the island mostly covered in sandy substrate. This can perhaps be attributed to the area being a route commonly used by boats from the islands to reach Banggi and Kudat, which might have affected coral growth. It is also exposed to waves and currents stronger than on the other, calmer side of the island, resulting in high turbulence and sedimentation to the west of the island. These conditions could affect coral growth and abundance (Lirman et al., 2003). 


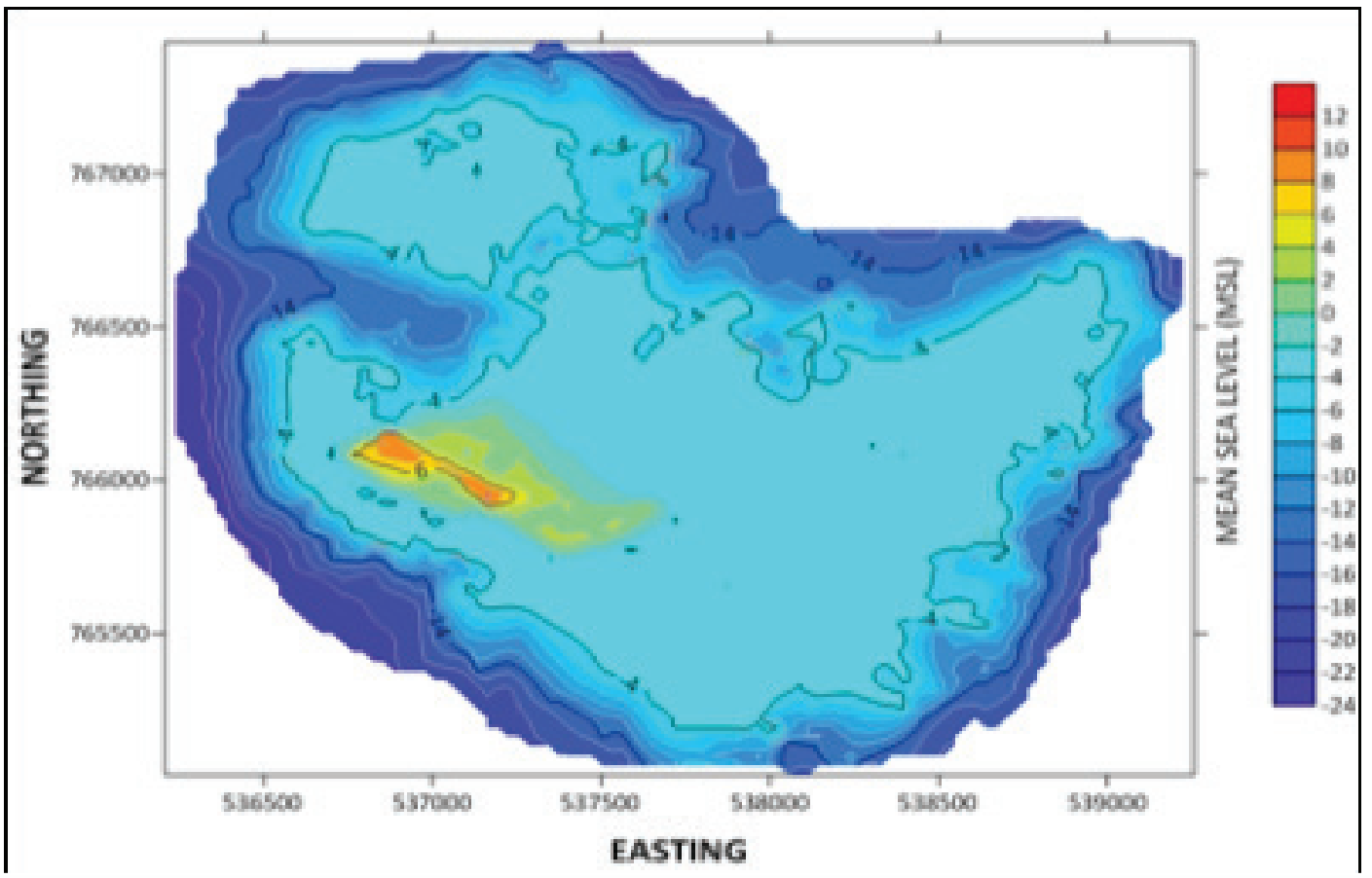

Figure 5.

Bathymetry map showing water depths around the Mandi Darah Island.

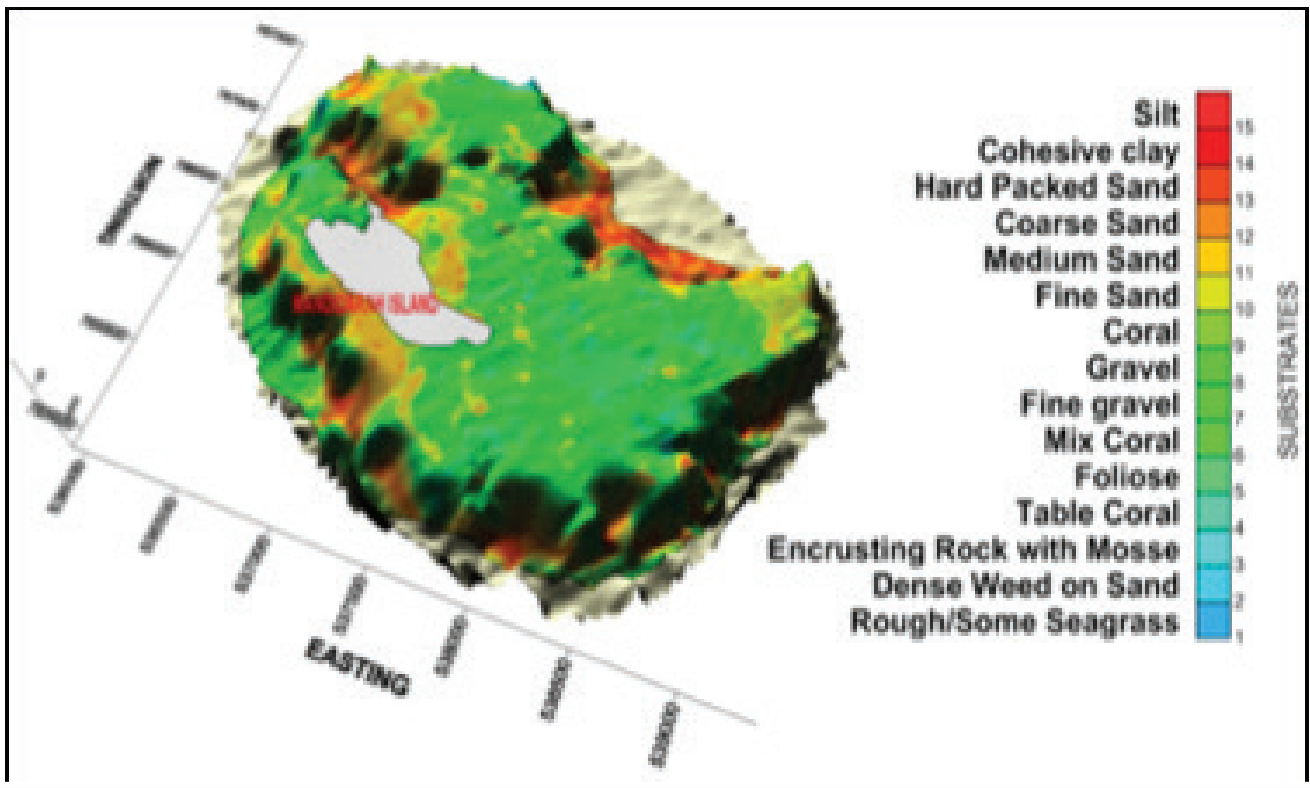

Figure 6.

3D interpolation map showing substrate distribution around the Mandi Darah Island. 
The acoustic approach described in this paper is suitable for seabed substrate mapping in moderately clear waters, such as those surrounding the Mandi Darah Island. The traditional scuba diving approach to direct measurement and visual survey remains one of the most dependable survey methods for gathering seafloor information. Yet, this traditional method is highly risky for the diver, not cost-efficient, cumbersome, and impractical for producing maps covering larger areas. Acoustic methods using echo sounders would be more practical for mapping wide areas, as they take less time and require less manpower than the traditional scuba diving approach (Abdullah et al., 2016). In contrast, the satellite remote sensing approach is capable of covering a larger area in less time. Albeit, although this is an advantage, satellite remote sensing only works in shallow and clear waters, as the light decreases within the water column. Heavy clouds common in the equatorial region such as Malaysia are a serious problem for satellite remote sensing and often hampered data collection. In addition, due to the territorial and radiometric resolution of satellite visuals, this methodology also has restrictions with respect to the identification of particulars of a tiny, dispersed or low-populated seafloor habitat (Komatsu, 2003). In this instance, the acoustic approach is more suitable for substrate mapping in Malaysian waters.

\section{CONCLUSION}

This study has successfully explored the seabed substrate of the Mandi Darah Island, using RoxAnn GD-X and high-frequency single-beam echo sounder. The acoustic data obtained were color coded to represent the variations of the seabed substrate characteristic for the study area. A total of 15 types of substrate have been identified and classified, ranging from silt to rough/ some seagrass. The application of the acoustic approach in this study has demonstrated its capability to identify seabed substrates at low cost and in a relatively small area. For further research, this method could become an alternative to and complement the traditional methods that use direct observation techniques, such as video, scuba diving, etc. The acoustic technique also has the advantage of facilitating the rapid surveying of turbid waters. Although the acoustic approach gives good results, since this study employed AGDS with a single-beam echo sounder, an interpolation between survey lines is required, as it frequently resulted in the misclassification of seabed substrates. Future studies should therefore use a multi-beam echo sounder capable of full seafloor coverage for seabed substrate mapping.

\section{ACKNOWLEDGEMENTS}

The authors would like to acknowledge the support received from the National Defence University of Malaysia and the Ministry of Energy and Natural Resources for a part of its multidisciplinary research grant (UPNM/2018/AAIBE-KETTHA/ TK/1/P2), as well as to Geohydrocean Services Sdn. Bhd. for technical advice and data collection at the site.

\section{REFERENCES}

Abdullah, A. L. et al., 2016. Conservation of pulau payar marine park and optical remote sensing models. Kemanusiaan, 23, pp. 79-107.

Baker, E.K. \& Harris, P.T., 2012. Habitat Mapping and Marine Management. Seafloor Geomorphology as Benthic Habitat, pp.23-38. Available at: http://dx.doi.org/10.1016/b978-0-12-385140-6.00002-5.

Biondo, M. \& Bartholomä, A., 2017. A multivariate analytical method to characterize sediment attributes from high-frequency acoustic backscatter and ground-truthing data (Jade Bay, German North Sea coast). Continental Shelf Research, 138, pp.65-80. Available at:

http://dx.doi.org/10.1016/j.csr.2016.12.011.

Brown, C.J. et al., 2005. Mapping seabed habitats in the Firth of Lorn off the west coast of Scotland: evaluation and comparison of habitat maps produced using the acoustic ground-discrimination system, RoxAnn, and sidescan sonar. ICES Journal of Marine Science, 62(4), pp.790-802. Available at: http://dx.doi.org/10.1016/j.icesjms.2004.10.008.

Coiras, E., Myers, V. \& Evans, B., 2007. Reliable Seabed Characterization for MCM Operations. OCEANS 2007. Available at: http://dx.doi.org/10.1109/oceans.2007.4449126.

Conti, L.A., Torres da Mota, G. \& Barcellos, R.L., 2020. High-resolution optical remote sensing for coastal benthic habitat mapping: A case study of the Suape EstuarineBay, Pernambuco, Brazil. Ocean \& Coastal Management, 193, p.105205. Available at: http://dx.doi.org/10.1016/j.ocecoaman.2020.105205.

Fakiris, E. et al., 2019. Multi-Frequency, Multi-Sonar Mapping of Shallow HabitatsEfficacy and Management Implications in the National Marine Park of Zakynthos, Greece. Remote Sensing, 11(4), p.461. Available at:

http://dx.doi.org/10.3390/rs11040461.

Foster-Smith, R.L. \& Sotheran, I.S., 2003. Mapping marine benthic biotopes using acoustic ground discrimination systems. International Journal of Remote Sensing, 24(13), pp.2761-2784. Available at: http://dx.doi.org/10.1080/0143116031000066323a.

Garcia, R. et al., 2015. A Method to Analyze the Potential of Optical Remote Sensing for Benthic Habitat Mapping. Remote Sensing, 7(10), pp.13157-13189. Available at: http://dx.doi.org/10.3390/rs71013157.

Hamana, M. \& Komatsu, T., 2016. Real-Time Classification of Seagrass Meadows on Flat Bottom with Bathymetric Data Measured by a Narrow Multibeam Sonar System. Remote Sensing, 8(2), p.96. Available at: http://dx.doi.org/10.3390/rs8020096. 
Hamilton, L.J., 2001. Acoustic seabed classification systems. DSTO Technical Note DSTO-TN-0401.66. Available at: http://www.dsto.defence.gov.au/corporate/reports/ DSTO-TN-0401.pdf.

Che Hasan, R. et al., 2014. Integrating Multibeam Backscatter Angular Response, Mosaic and Bathymetry Data for Benthic Habitat Mapping S. Thrush, ed. PLoS ONE, 9(5), p.e97339. Available at:

http://dx.doi.org/10.1371/journal.pone.0097339.

Herkül, K., Peterson, A. \& Paekivi, S., 2017. Applying multibeam sonar and mathematical modeling for mapping seabed substrate and biota of offshore shallows. Estuarine, Coastal and Shelf Science, 192, pp.57-71. Available at: http://dx.doi.org/10.1016/j.ecss.2017.04.026.

Hossain, M.S. et al., 2016. Marine and human habitat mapping for the Coral Triangle Initiative region of Sabah using Landsat and Google Earth imagery. Marine Policy, 72, pp.176-191. Available at: http://dx.doi.org/10.1016/j.marpol.2016.07.003.

Jawak, S.D., Vadlamani, S.S. \& Luis, A.J., 2015. A Synoptic Review on Deriving Bathymetry Information Using Remote Sensing Technologies: Models, Methods and Comparisons. Advances in Remote Sensing, 04(02), pp.147-162. Available at: http://dx.doi.org/10.4236/ars.2015.42013.

Biondo, M. \& Bartholomä, A., 2017. A multivariate analytical method to characterize sediment attributes from high-frequency acoustic backscatter and ground-truthing data (Jade Bay, German North Sea coast). Continental Shelf Research, 138, pp.65-80. Available at:

http://dx.doi.org/10.1016/j.csr.2016.12.011

Lirman, D. et al., 2003. Coral communities of Biscayne Bay, Florida and adjacent offshore areas: diversity, abundance, distribution, and environmental correlates. Aquatic Conservation: Marine and Freshwater Ecosystems, 13(2), pp.121-135. Available at:

http://dx.doi.org/10.1002/aqc.552.
Monaliza, M.D., \& Samsur, M., 2011. Toxicity and Toxin Properties Study of Puffer Fish Collected from Sabah Waters. Health and the Environment Journal, 2(1), pp. 14-17.

Marine and Coastal Biodiversity, 2015. Marine and coastal biodiversity offsets. Available at: https://www.mybis.gov.my/art/6.

Mustapha, M. A., Lihan, T., \& Khalid, L. I., 2014. Coral reef and associated habitat mapping using ALOS satellite imagery. Sains Malaysiana, 43(9), pp. 1363-1371.

Papakonstantinou, A., Stamati, C. \& Topouzelis, K., 2020. Comparison of True-Color and Multispectral Unmanned Aerial Systems Imagery for Marine Habitat Mapping Using Object-Based Image Analysis. Remote Sensing, 12(3), p.554. Available at: http://dx.doi.org/10.3390/rs12030554

Reef Check Malaysia., 2020. 2020 Status of Coral Reefs. p.128.

Rukavina, N., 2001. Mapping and monitoring contaminated-sediment geometry and stability. The Science of The Total Environment, 266(1-3), pp.33-39. Available at: http://dx.doi.org/10.1016/s0048-9697(00)00738-5.

Sabah Parks., (2017). Tun Mustapha Park. The Official Website of the Board of Trustees of the Sabah Parks.

Schimel, A.C.G. et al., 2010. Quantitative experimental comparison of single-beam, sidescan, and multibeam benthic habitat maps. ICES Journal of Marine Science, 67(8), pp.1766-1779. Available at:

http://dx.doi.org/10.1093/icesjms/fsq102.

Suadik, M. et al., 2018. Sumber semula jadi dan kepentingannya terhadap sosioekonomi komuniti pesisir Pantai Timur Sabah. Jurnal Kinabalu, 21, pp. 1-19.

Tajam, J., \& Mokhtar, M., 2019. Marine Habitat Distribution and Substrate Composition of Dangli Group of Islands, Langkawi UNESCO Global Geopark, Kedah, Malaysia. International Journal of Oceans and Oceanography, 13(1), pp. 37-56.

Yap, K., 2017. An Attempt Using Hydro-Acoustic Approach for Rapid Coral Reef Mapping in Malaysia. 